\title{
QUALIDADE DE VIDA DO TRABALHADOR “COMO OS PROGRAMAS DE QVT PODEM MELHORAR O DESEMPENHO DOS MOTORISTAS DE TRANSPORTE DE PRODUTOS PERIGOSOS."
}

\author{
WORKERS' QUALITY OF LIFE \\ "HOW QVT PROGRAMS CAN IMPROVE THE PERFORMANCE OF HAZARDOUS PRODUCT \\ TRANSPORT DRIVERS."
}

Juliana Soares Felix¹, Julio Cesar Moledo².

\begin{abstract}
RESUMO
Este artigo apresenta um breve estudo sobre QVT - qualidade de vida do trabalhador. Serão mostrados alguns processos de trabalho, abordando formas e normas regulamentadoras ergonômicas e motivos e causas de acidentes nas principais rodovias e modelo do QVT, para Nadler e Lawler, Hackman e Walton e apresentar os direitos dos motoristas conforme a legislação CLT, logística empresarial, fatores motivacionais, higiênico e programas QVT. Serão apresentadas sugestões que podem ser implantadas nos programas de qualidade de vida do trabalhador no setor de transportadoras de produtos químicos, para que possa trazer mais motivações para os motoristas que passa a maior parte do tempo nas rodovias. Assim podendo deixar claro que a qualidade de vida do indivíduo também depende da qualidade de vida no trabalho, pois o trabalho assume papel central na vida das pessoas. Qualidade de vida é trabalhar, onde se sente bem com transparência nas relações internas, equilíbrio econômico e criatividade. A maior ênfase é de que se pode implantar programas que possam trazer satisfação, dando uma qualidade melhor para seus colaboradores e trazendo satisfação e qualidade no serviço para as organizações.
\end{abstract}

PALAVRAS-CHAVE: QVT. Transportadora de produto químico. Funcionários. Necessidades.

\begin{abstract}
This article presents a brief study on QWL - worker quality of life. Some work processes will be presented, addressing ergonomic regulatory forms, standards, causes, and causes of accidents on QVT major highways and model, for Nadler and Lawler, Hackman and Walton and presenting driver rights under CLT legislation, business logistics, factors motivational, hygienic and QVT programs. Suggestions will be presented that can be implemented in the quality of life programs of workers in the chemical carriers sector, so that it can bring more motivations for drivers who spend most of the time on the highways. Thus, it can be made clear that the quality of life of the individual also depends on the quality of life at work, because work takes a central role in people's lives. Quality of life is work, where it feels good with transparency in internal relationships, economic balance and creativity. The major emphasis is that programs can be implemented that can bring satisfaction, giving a better quality to its employees and bringing satisfaction and quality in service to organizations.
\end{abstract}

KEYWORDS: QVT. Chemical carrier. Employees. Needs.

1 Bacharelado em Administração de Empresas. - Universidade UNG, Campus Itaquaquecetuba.

2 Professor orientador do Trabalho de Conclusão do Curso de Bacharelado em Administração de Empresas. 


\section{INTRODUÇÃO}

O presente trabalho de conclusão de curso tem como finalidade mostrar a partir de estudo os conceitos básicos da qualidade de vida do trabalhador (QVT). Sendo esse um fenômeno inerente a essa parcela de trabalhadores.

Apresentar sugestões de ações e programas de QVT diferenciado, visando a melhoria do desempenho do trabalhador para ganho das organizações.

Como já destacada anteriormente a qualidade de vida desse profissional sofre atitudes pessoas e comportamentais que interferem na produtividade grupal. Nessa perspectiva algumas mudanças são significativas para esse processo, como motivação, adaptabilidade, criatividade, inovação e ética de valores organizacionais.

O interesse pelo tema "Qualidade de Vida do Trabalhador" como trabalho de conclusão de curso (TCC) surgiu da inquietação de melhor entender como se da essa relação desse profissional no mercado de trabalho.

O trabalho tem como objetivo traçar um percurso do processo de trabalho, abordando formas e normas regulamentadoras ergonômicas e motivos e causas de acidentes nas principais rodovias e apresentar modelo do QVT, para Nadler e Lawler, Hackman e Walton e apresentar os direitos dos motoristas conforme a legislação CLT, logística empresarial, fatores motivacionais, higiênico e programas QVT.

Assim se enfatizar o esclarecimento da atuação desse profissional, ouvindo, esclarecendo sobre a importância desse profissional de acordo com a legislação CLT.

\section{FUNDAMENTAÇÃO TEÓRICA}

O setor de transporte rodoviário de carga perigosa sofre com a falta de motoristas no mercado, por causa da desvalorização dos profissionais sendo que eles possuem uma carga horaria levando e trazendo, com a insuficiência de programas de qualidade de vida, onde levam os motoristas desenvolver alterações metabólicas, alterações comportamentais nocivas à saúde, estresse, débito de sono, desprazer, sedentarismo entre outros.
Pouca atenção tem sido dada para os motoristas de transportadoras de produtos perigosos, deixando de levar em consideração o profissionalismo e o comprometimento deles e esquecendo as necessidades humanas.

Muitas transportadoras não utilizam de comprometimento e valorização para com os seus colaboradores, negligenciando o fato de que são fundamentais dentro das organizações e que necessitam da sua mão de obra para se ter produtividade.

Necessitamos então de uma visão mais ampla dentro das empresas, que possam analisar as necessidades e melhorar as condições dos motoristas, podendo trazer qualidade de vida e segurança, assim evitando riscos graves para os colaboradores.

O departamento de Recursos Humanos deve ter uma visão mais ampla com mais responsabilidade, para que eles possam trabalhar com mais objetividade e para que evite a empresa ter problemas com turnover e absenteísmo, onde passa ocorrer um custo muito alto para a empresa. Sendo assim o departamento deve se posicionar junto com a gestão, criando um programa de qualidade permitindo que se tenha um dos motoristas como representante dos comitês em reuniões onde visem interesses da equipe, e que possam transmitir tanto a exigência da empresa como as necessidades dos motoristas, levando em consideração da melhor forma possível para ambos podendo trabalhar em conjunto, trazendo melhorias do setor de transportes evitando a escassez da profissão dos motoristas de transportes,

A ideia é apresentar também o modelo do QVT, para Nadler e Lawler, Hackman e Walton e apresentar os direitos dos motoristas conforme a legislação CLT, logística empresarial, fatores motivacionais, higiênico e programas QVT de transportadoras, que devem ser seguidos para poder evitar problemas futuros, que se relacione tanto aos motoristas como para as empresas.

O método utilizado será pesquisa bibliográfica realizada na literatura apresentada em artigos científicos disponíveis nos meios eletrônicos com consultas na base de dados Scielo, análise descritiva, onde terá como objetivo de mostrar a profissão de motorista de transportadoras que possuem agravantes para a saúde física e mental, com exposição a 
fatores nocivos á saúde e veículos com condições inadequadas fora dos padrões da ergonomia.

Também se utilizará de pesquisa da Lei do descanso; Lei 12.619/2012, Lei do Motorista; Jornada de trabalho, fatores motivacionais, higiênicos e os riscos nas rodovias por falta de mapeamento, dessa forma será muito importante para poder desenvolver o trabalho.

\subsection{Qualidade de vida do trabalho (QVT).}

Durante décadas ao mencionar "qualidade nas empresas", enfatizava-se a produção, atualmente essa visão é abrangente, pois não se trata apenas em qualidade no trabalho, mas também em qualidade de vida aos funcionários, surgindo assim a chamada QVT (Qualidade de vida no trabalho).

Segundo Paiva e Couto, (2008) o conceito de QVT envolve os aspectos físicos, ambientais e psicológicos do local de trabalho e o impacto disso no trabalhador.

Isso significa que os empregados precisam estar satisfeitos, para que seja produtivo, o trabalho que executam devem ser adequados a suas habilidades e necessitam de reconhecimento. A maior parte significativa da vida dos funcionários é dedicada ao trabalho, constituindo assim, maior fonte de identificação pessoal.

As pessoas, consequentemente, desejam trabalhar em lugares mais agradáveis, assim, as empresas são desafiadas a investir no ambiente, tanto para atrair talentos quanto para melhorar a produtividade do trabalho.

As empresas são desafiadas a implantar programas de qualidade de vida no trabalho que envolva também as dimensões relacionadas ao estilo gerencial, a liberdade e autonomia, para tomada de decisões e o oferecimento de tarefas significativas.

\subsubsection{Principais abordagens da QVT}

Alguns estudiosos dos Estados Unidos, França e outros países desenvolveram pesquisas importantes sobre a qualidade de vida no trabalho hoje considerada clássica. Esta seção apresenta a qualidade de vida no trabalho na visão dos autores Walton
(1973), Hackman e Oldham (1975) e Nadler, Hackman e Lawer (1983).

A abordagem de Walton considera que existem diversos fatores que juntos criam a QVT, existindo fatores que possam apresentar seu desenvolvimento organizacional.

\begin{tabular}{|c|c|}
\hline FATORES & DIMENSÕES \\
\hline \multirow{3}{*}{$\begin{array}{c}\text { Compensação justa e } \\
\text { adequada }\end{array}$} & Renda adequada ao trabalho \\
\hline & Equidade interna \\
\hline & Equidade externa \\
\hline \multirow{2}{*}{$\begin{array}{l}\text { Segurança e saúde nas } \\
\text { condições de trabalho }\end{array}$} & Jornada de trabalho \\
\hline & $\begin{array}{l}\text { Ambientes físicos, seguros e } \\
\text { saudáveis. }\end{array}$ \\
\hline \multirow{5}{*}{$\begin{array}{c}\text { Oportunidade imediata } \\
\text { para utilização e } \\
\text { desenvolvimento das } \\
\text { capacidades humanas }\end{array}$} & Autonomia \\
\hline & Significado da tarefa \\
\hline & Identidade da tarefa \\
\hline & Variedade de habilidades \\
\hline & Retro informação \\
\hline \multirow{3}{*}{$\begin{array}{l}\text { Oportunidade futura de } \\
\text { crescimento contínuo e } \\
\text { garantia profissional }\end{array}$} & Possibilidade de carreira \\
\hline & Crescimento profissional \\
\hline & Segurança de emprego \\
\hline \multirow{7}{*}{$\begin{array}{l}\text { Integração social na } \\
\text { organização }\end{array}$} & Igualdade de oportunidade \\
\hline & Relacionamento \\
\hline & Sento comunitário \\
\hline & $\begin{array}{l}\text { Respeito às leis e aos direitos } \\
\text { trabalhistas }\end{array}$ \\
\hline & Privacidade pessoal \\
\hline & Liberdade de expressão \\
\hline & Normas e rotinas \\
\hline $\begin{array}{l}\text { Trabalho e espaço total } \\
\text { da vida }\end{array}$ & Papel balanceado do trabalho \\
\hline \multirow{3}{*}{$\begin{array}{l}\text { Relevância social do } \\
\text { trabalho }\end{array}$} & Imagem da empresa \\
\hline & $\begin{array}{l}\text { Responsabilidade social pelos } \\
\text { serviços }\end{array}$ \\
\hline & $\begin{array}{l}\text { Responsabilidade social pelos } \\
\text { empregados }\end{array}$ \\
\hline
\end{tabular}

Fonte: Walton, 1973, Sant'Anna, Kilimnik e Moraes (2011).

Na abordagem de Nadler e Lawler, considera-se que a QVT obtém alguns aspectos e se estes forem promovidos, a consequência será a QVT.

De acordo com Chiavenato (2010), os aspectos para a geração do QVT são: 
- Participação dos colaboradores nas decisões;

- Reestruturação do trabalho por meio do enriquecimento de tarefas e de grupos autônomos de trabalho;

- Inovação no sistema de recompensas para influenciar o clima organizacional;
- Melhoria no ambiente de trabalho quanto a condições físicas e psicológicas, horário de trabalho e outros aspectos

O quadro abaixo ilustra de maneira detalhada esses princípios.

Quadro 2 - Abordagem de Nadler e Lawler (1983)

\begin{tabular}{|c|c|c|}
\hline PERÍODO & FOCO PRINCIPAL & DEFINIÇÃO \\
\hline 1959/1972 & Variável & $\begin{array}{l}\text { A QVT foi tratada como reação individual ao trabalho ou às consequências } \\
\text { pessoais de experiências do trabalho. }\end{array}$ \\
\hline $1969 / 1975$ & Abordagem & $\begin{array}{l}\text { A QVT dava ênfase ao indivíduo antes de dar ênfase aos resultados } \\
\text { organizacionais, mas ao mesmo tempo era vista como um elo dos projetos } \\
\text { cooperativos do trabalho gerencial. }\end{array}$ \\
\hline $1972 / 1975$ & Método & $\begin{array}{l}\text { A QVT foi o meio para o engrandecimento do ambiente de trabalho e a } \\
\text { execução de maior produtividade e satisfação. }\end{array}$ \\
\hline $1975 / 1980$ & Movimento & $\begin{array}{c}\text { A QVT como movimento, visa a utilização dos termos "gerenciamento } \\
\text { participativo" e "democracia industrial" com bastante frequência, invocador } \\
\text { como ideais do movimento. }\end{array}$ \\
\hline $1979 / 1983$ & Tudo & $\begin{array}{c}\text { A QVT é vista como um conceito global e como forma de enfrentar os } \\
\text { problemas de qualidade e produtividade. }\end{array}$ \\
\hline Previsão Futura & Nada & $\begin{array}{l}\text { A globalização da definição trará como consequência inevitável a descrença de } \\
\text { alguns setores sobre o termo QVT. E para estes QVT nada representará. }\end{array}$ \\
\hline
\end{tabular}

Fonte: Rodrigues, 2011, p. 81.

O modelo de Hackman e Oldham segundo Paiva e Couto (2008) relatam que a QVT está relacionada com as características das atividades exercidas, sendo assim relacionam-se com as dimensões básicas das tarefas, das quais, por sua vez, influenciam psicologicamente o empregado, impactando a sua produtividade.

Quadro 3 - Modelo de Hackman e Oldham (1975)

\begin{tabular}{|c|}
\hline DIMENSÕES DA TAREFA \\
\hline VH - Variedade de Habilidades \\
\hline IT - Identidade da Tarefa \\
\hline ST - Significância da Tarefa \\
\hline AU - Autonomia \\
\hline FI - Feedback Intrínseco \\
\hline FE - Feedback Extrínseco \\
\hline IR - Inter-Relacionamento \\
\hline
\end{tabular}

Fonte: Hackman e Oldham (1975)
A QVT deve ter uma visão global, o trabalhador tem que fazer parte do processo, produzindo e participando do gerenciamento.

A busca de parcerias com clientes, fornecedores e funcionários tornaram-se fundamental nesse processo. Favorecer o desenvolvimento de um perfil humano condizente com os padrões do paradigma imergente consiste em construir os alicerces para uma organização inteligente e inovadora. Respeitar o trabalhador como "ser humano" significa contribuir para a construção de um mundo mais humano e para um desenvolvimento sustentável. Investimento em qualidade de vida significa investimento no progresso da sociedade e da economia global.

Atualmente, com a globalização, as organizações utilizam outros modelos de QVT, como a mudança global de enfoque, visando assim melhorar as condições de competitividade, lucratividade e qualidade dos produtos e serviços. 
Quadro 4 - Mudança global de enfoque

\begin{tabular}{|c|c|}
\hline De & Para \\
\hline $\begin{array}{c}\text { Visão específica } \\
\text { Sistema fechado (Foco no } \\
\text { produto) }\end{array}$ & $\begin{array}{c}\text { Sistema Aberto (Foco no } \\
\text { mercado) }\end{array}$ \\
\hline $\begin{array}{c}\text { Ênfase no passado ("O que } \\
\text { já foi feito") }\end{array}$ & $\begin{array}{c}\text { Ênfase no futuro ("O que } \\
\text { será possível fazer") }\end{array}$ \\
\hline $\begin{array}{c}\text { Qualidade vista como custo } \\
\text { Qualidade vista como } \\
\text { investimento }\end{array}$ \\
\hline $\begin{array}{c}\text { Abordagem padronizada e } \\
\text { burocrática }\end{array}$ & $\begin{array}{c}\text { Abordagem cada vez mais } \\
\text { dinâmica }\end{array}$ \\
\hline $\begin{array}{c}\text { Busca de "otimização numa } \\
\text { esfera limitada" }\end{array}$ & $\begin{array}{c}\text { Busca de "sinergia numa } \\
\text { esfera cada vez mais ampla" }\end{array}$ \\
\hline A Gestão da Qualidade & A Qualidade da Gestão \\
\hline
\end{tabular}

Fonte: Barçante, L. C. \& Castro, G. C. Ouvindo a Voz do Cliente Interno, p. 9. Rio de Janeiro: QualityMark, 1995. (atualizado)

\subsubsection{Higiene do trabalho}

A higiene do Trabalho relaciona-se com a vida do trabalhador dentro das organizações.

De acordo com Chiavenato (2015, p.136) a higiene do Trabalho refere-se a um conjunto de normas e procedimentos que visa à proteção da integridade física e mental do trabalhador, preservando-o dos riscos de saúde inerentes às tarefas do cargo e ao ambiente físico onde são executados.

A higiene do trabalho ou higiene ocupacional está relacionado com condições ambientais de trabalho e com as condições de bem-estar delas. Do ponto de vista de saúde físico, o local de trabalho é a área de ação da higiene do trabalho, envolvendo os aspectos ligados com a exposição do organismo humano a agentes externos, como ruídos, ar, temperatura, umidade luminosidade e equipamentos.

Assim, um ambiente saudável de trabalho deve envolver condições ambientais físicas que atuem positivamente sobre todos os órgãos dos sentidos humanos - visão, audição, tato, olfato e paladar.

Do ponto de vista de saúde mental, o ambiente de trabalho deve envolver condições psicológicas e sociológicas saudáveis e que atuem positivamente sobre o comportamento das pessoas, evitando impactos emocionais, como por exemplo o estresse.
Os principais itens do programa de higiene do trabalho estão relacionados com:

\section{Ambiente físico de trabalho}

- Iluminação: luminosidade adequada a cada tipo de atividade;

- Ventilação: remoção de gases, fumaças e odores desagradáveis, bem como o afastamento de possíveis fumantes ou a utilização de máscaras;

- Temperatura: manutenção de níveis adequados de temperatura;

- Ruídos: remoção de ruídos ou utilização de protetores auriculares;

\section{Ambiente psicológico de trabalho:}

- Relacionamentos humanos agradáveis;

- Tipo de atividade agradável e motivadora;

- Estilo de gerência democrático e participativo;

- Eliminação de possíveis fontes de estresse.

\section{Aplicação de princípios de ergonomia:}

- Máquinas e equipamentos adequados às características humanas;

- Mesas de instalações ajustadas ao tamanho das pessoas;

- Ferramentas que reduzam a necessidade de esforço físico humano;

\section{Saúde ocupacional:}

- regulamentada em nível superior,

- trabalha com atividades humanas,

- planeja e organiza o cotidiano,

- possibilitando melhor qualidade de vida.

\subsubsection{Estresses no trabalho}

Estresse é um conjunto de reações físicas, químicas e mentais de uma pessoa decorrente de estímulos ou estressores que existem no ambiente. É uma condição dinâmica que surge quando uma pessoa é confrontada com uma oportunidade, restrição ou demanda relacionada com o que ela deseja. 
O estresse é a soma das perturbações orgânicas e psíquicas provocadas por diversos agentes agressores, como: traumas, emoções fortes, fadiga, exposição a situações conflitivas e problemáticas com chefes ou clientes provocam reações como nervosismo, inquietude, tensão, etc.

A função básica do estresse no organismo é manter a homeostase, assim melhorando a sua capacidade, para se garantir a sua sobrevivência.

Quando comparamos o indivíduo estressado com o seu trabalho, podemos constatar que a sua personalidade é reflexo de seu trabalho, ou seja, no mundo globalizado onde temos o trabalho como um dos principais focos de vida, observamos que a maioria da população não é satisfeita com as suas atribuições e suas condições de trabalho.

Atualmente, os estudos e as publicações sobre stress e seus efeitos abrangem não só as consequências do stress no corpo e na mente humana, mas também para a qualidade de vida da humanidade. (LIPP,1996, p. 19).

O autoritarismo do chefe, desconfiança, pressão das exigências e cobranças, cumprimentos do horário de trabalho, chatice e monotonia de certas tarefas, o baixo-astral dos colegas, a falta de perspectiva de progresso profissional e insatisfação pessoal não somente derrubam o bom humor das pessoas como também provocam estresse no trabalho.

Segundo Villa-Lobos (1999), o estresse ocupacional é o conjunto de fenômenos que se sucedem no organismo do trabalhador com a participação dos agentes estressantes lesivos derivados diretamente do trabalho ou por motivo deste, e que podem afetar a saúde do trabalhador.

Podemos verificar que o estresse, que é causado pelas atribuições ocupacionais do indivíduo, tem impacto totalmente significativo em sua estrutura de vida, afetando sua saúde, o incapacitando assim de desenvolver com plenitude suas atribuições.
Figura 1 - Estressores na vida de cada pessoa.

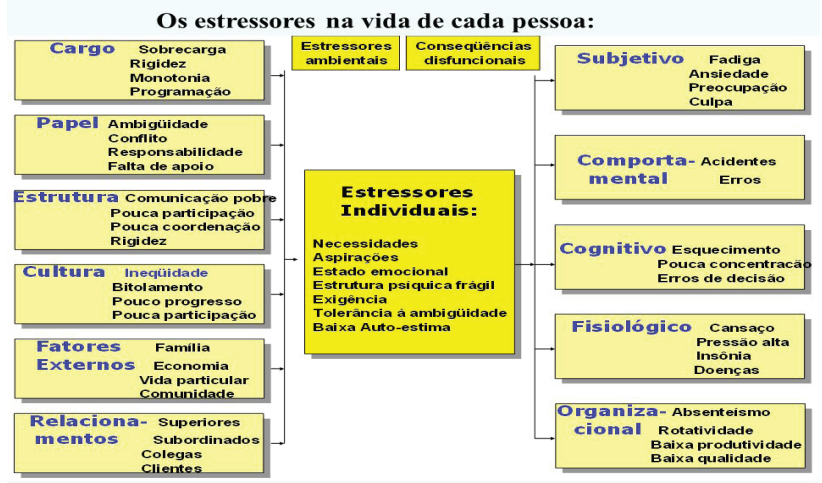

Fonte: Gestão de pessoas: o novo papel dos recursos humanos nas organizações/ Idalberto Chivenato. 4. Ed - Barueri, SP: Manuel, 2014.

Existem duas fontes principais de estresse no trabalho: causas ambientais e causas pessoais, o estresse no trabalho provoca sérias consequências tanto para colaborador quanto para a organização.

Essas consequências em sua saúde atrapaIham o colaborador em diversas fases de sua vida corporativa.

\section{MOTIVAÇÃO}

O motivo ou a motivação tratam sobre a finalidade que se destinam a uma finalidade que resultam das finalidades de empenho.

Motivação refere-se às forças que energizam, dirigem e sustentam os esforços de uma pessoa na realização de objetivos proposto.

Segundo Daft (2005, p. 398) a motivação refere-se às forças internas ou externas para uma pessoa que estimulem o seu entusiasmo e sua persistência para perseguir certos custos de ação. A motivação dos funcionários afeta a produtividade, e parte do trabalho do gerente é canalizar a motivação em direção à realização das metas organizacionais.

O estudo da motivação ajuda os gerentes a entender (SIC) o que estimula as pessoas a iniciarem a ação o que influencia suas escolhas de ações e porque com o tempo elas persistem naquelas ações.

Para Chiavenato (1999) "A motivação e o desejo de exercer altos níveis de esforço em direção e determinados objetivos organizacionais, condicionados 
pela capacidade de satisfazer objetivos individuais“.

Podemos constatar que segundo as suas crenças, Chiavenato atribui o fato de que os objetivos do indivíduo na organização, sejam satisfazer os objetivos individuais que estão inteiramente ligados com a capacidade de autorrealização do ser humano.

Daft (2005, p. 400-401), ainda cita Abrahan Maslow, e afirma que "Maslow identificou cinco tipos gerais de necessidades motivacionais em ordem de ascendência".

\subsection{Teoria das Necessidades Humanas Básicas}

A famosa hierarquia das necessidades de Maslow, proposta pelo psicólogo americano Abraham Maslow, baseia-se na ideia de que cada ser humano se esforça muito para satisfazer suas necessidades pessoais e profissionais. É um esquema que apresenta uma divisão hierárquica em que as necessidades consideradas de nível mais baixo devem ser satisfeitas antes das necessidades de nível mais alto. Segundo esta teoria, cada indivíduo tem de realizar uma "escalada" hierárquica de necessidades para atingir a sua plena autorrealização. (PERIARD, 2006).

Sendo assim, podemos relevar a importância de que a teoria das Necessidades Básicas de Maslow tem com a qualidade de vida, no qual buscamos o enfoque na QTV.

Abaixo temos de forma simplificada a relação entre a teoria das Necessidades Básicas interagindo com o indivíduo em si.

Figura 2- Tipos de Necessidades Básicas Abraham Maslow.

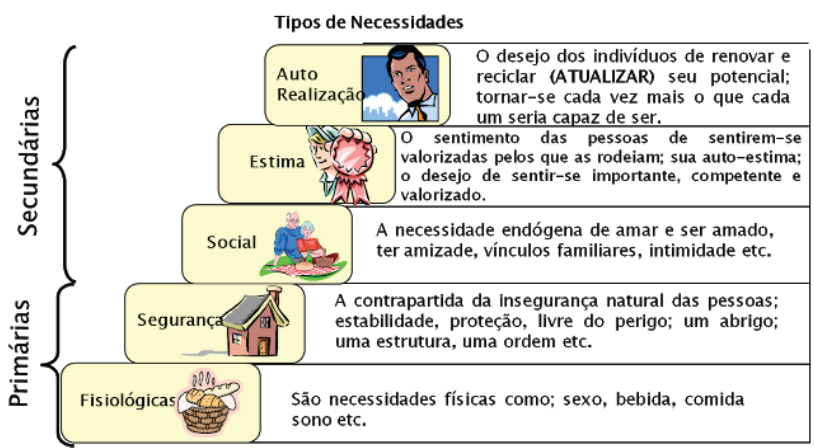

Fonte: http://gti.projetointegrador.com. br/ 152M154200129/lozzi.html
- Necessidade de autorrealização: representa a necessidade de autorrealização, que é a categoria das necessidades mais altas. Elas se referem ao desenvolvimento do potencial pleno de uma pessoa, aumentando a sua competência e tornando alguém melhor. As necessidades de autorrealização podem ser satisfeitas na organização, proporcionando as pessoas oportunidades de crescimento, de serem criativas de adquirirem treinamento para tarefas desafiadoras e pregressas.

- Necessidades de estima: Essas necessidades se relacionam ao desejo de uma outoimagem positiva e de receber atenção, reconhecimento e apreciação dos outros dentro das organizações, as necessidades de estima refletem uma motivação pelo reconhecimento, um aumento na responsabilidade, alto status e credito pelas contribuições feitas a organização;

- Necessidades sociais: Essas necessidades refletem o desejo de ser aceito pelos colegas, ter amizades, ser parte de um grupo e ser amado na organização, essas necessidades influenciam o desejo de bons relacionamentos com os colegas a participação em grupo de trabalho e relacionamento positivo com supervisores;

- Necessidades de segurança: Essas são as necessidades para um ambiente físico e emocional seguro e livre de ameaças - isto é, pela liberdade contra violência e por uma sociedade em ordem. Em um local de trabalho organizacional as necessidades de seguranças refletem as necessidades de tarefas seguras, benefícios extras e seguranças no trabalho;

- Necessidades Fisiológicas: Essas são necessidades físicas, humanas mais básicas, incluindo alimento, água e oxigênio no ambiente organizacional, elas estão refletidas nas necessidades para aquecimentos adequados, salário base para garantir a sobrevivência;

É possível admitir que a motivação cause au- 
mentos significativos na produtividade e na satisfação no trabalho, além de diminuir consideravelmente o absenteísmo.

Necessidades não satisfeitas ou não atendidas também são entendidas como elementos motivados, pois direcionam os colaboradores a atividades que visam atenuar ou suprir tais necessidades e isso reduz a tensão que outrora havia se instalado no clima organizacional de determinado setor ou de determinada organização.

A motivação pode ser considerada, como um processo que, ao ser deflagrado, estimula a tomada de decisões que visem suprir necessidades ou alcançar metas estipuladas. E para que este cenário se concretize é necessária a presença de ser líder atuante, seja por meio da motivação, seja por meio de empowerment.

\section{LEGISLAÇÃO}

Segundo a Agencia Nacional de Transportes Terrestres (ANTT), a Lei 10.233, de 05 de junho de 2001, ao promover uma reestruturação no setor federal de transporte, estabeleceu em seu artigo 22, inciso VII, que compete à ANTT regulamentar o transporte de cargas e produtos perigosos em rodovias e ferrovias.

O regulamento brasileiro do transporte rodoviário de produtos perigosos baseia-se nas recomendações emanadas pelo Comitê de Peritos em Transporte de Produtos Perigosos das Nações Unidas, que são atualizadas periodicamente, e publicadas no Regulamento Modelo conhecido como "Orange Book", bem como no Acordo Europeu para o Transporte Rodoviário.

O transporte rodoviário, por via pública, de produtos que sejam perigosos, por representarem risco para a saúde de pessoas, para a segurança pública ou para o meio ambiente, é submetido às regras e aos procedimentos estabelecidos pelo Regulamento para o Transporte Rodoviário de Produtos Perigosos, Resolução ANTT nº. 3665/11 e alterações, complementado pelas Instruções aprovadas pela Resolução ANTT.

Segundo a SETCESP (Sindicato das Empresas de Transporte de Cargas de São Paulo), ANTT (Agencia Nacional de Transportes Terrestres), Tra- ckingsystem e Região e o Congresso Nacional decreta e sanciona a seguinte Lei:

Jornada de trabalho de 8 horas e a possível prorrogação por mais 2 horas extras, desde que acordado com o empregado.

A jornada de trabalho será de 44 horas semanais, fora a hora extra. Como já prevê a lei atual, será assegurado o intervalo mínimo de 1 hora para refeição e um descanso entre jornadas de 11 horas, conforme já prevê os artigos 71 e 66 da CLT, respectivamente. O descanso semanal passa a ser de 35 horas ao invés de 24 horas, e nas viagens de longa distância, que também falaremos mais adiante, o período é de 36 horas. 0 excesso de jornada, ou seja, as horas extras poderão ser compensadas em outro dia, conforme previsão em convenção coletiva ou acordo coletivo. (SETCESP - Sindicato das Empresas de Transporte de Cargas de São Paulo e Região).

Podemos constar através do seguinte exemplo, que se o motorista desempenha seu horário de serviço a partir das $8 \mathrm{~h} 00$ da manhã e sai às $17 \mathrm{~h} 00$ da tarde, perfaz um total de oito horas trabalhadas, excluída uma hora para almoço. O mesmo faz mais duas horas extra, ou seja, sua jornada de trabalho vai até às $19 \mathrm{~h} 00$. Porém, ele está no destinatário descarregando a mercadoria e isto demora mais duas horas e meia, ou seja, sua jornada vai até as $21 \mathrm{~h} 30$. Estas duas horas e meia após as horas extras são consideradas tempo de espera. O tempo de espera é indenizado com base no salário-hora, acrescido de mais $30 \%$ (trinta por cento). O caráter indenizatório desta verba, como descrito no parágrafo $9^{\circ}$ do artigo 235-C da Lei 12.619/11, permite-nos dizer que a mesma não terá incidência de nenhum encargo (INSS, FGTS, IRRF) e nem comporá os cálculos de férias, $13^{\circ}$, verbas rescisórias e etc.

Para os motoristas que fazem viagens de longa distância, assim considerado quando o mesmo ficar mais de 24 horas fora de sua residência e local de trabalho (matriz ou filial), a cada 4 horas dirigindo de forma ininterrupta, o mesmo deve parar 30 minutos. Se houver paradas antes de completadas as 4 horas de direção, estes tempos poderão ser descontados 
dos 30 minutos. Também é garantido o mínimo de 1 hora para refeição, podendo coincidir com os 30 minutos de descanso acima citado. Ou seja, dentro da 1 hora de descanso, já se considera os 30 minutos de descanso após quatro horas ininterruptas de direção, caso haja coincidência.

O intervalo entre jornadas deve ser respeitado, ou seja, mesmo o motorista que faz viagens de longo percurso deve descansar 11 horas. Este descanso pode ser feito no caminhão que tenha cabine para isso, dentro de dormitórios fornecidos pela empresa, pelo embarcador, pelo contratante do serviço ou no destinatário, bem como em hotel. Para as empresas que adotarem o sistema de dois motoristas no mesmo caminhão nas viagens de longa distância, o repouso poderá ser na cabine enquanto o outro dirige. Entretanto, ao menos 6 horas serão com o veículo parado.

As horas de descanso no veículo em movimento serão consideradas tempo de reserva, e serão remuneradas à razão de $30 \%$ da hora normal. Neste caso há incidência de encargos sociais e reflexos em verbas trabalhistas.

Nas viagens que ultrapassarem a uma semana, o descanso semanal será de 36 horas por semana, e seu gozo se dará no retorno do motorista a sua base, salvo se a empresa oferecer condições adequadas para o efetivo descanso, quando então poderá gozar antes este direito. Este repouso de 36 horas pode ser fracionado em 30 horas de descanso direto e 6 horas na mesma semana do descanso, desde que ocorra após um descanso diário, ou seja, após 11 horas de descanso.

É obrigação de o empregador oferecer aos seus motoristas empregados um seguro obrigatório às suas expensas, destinado à cobertura dos riscos pessoais inerentes às atividades profissionais, o valor mínimo de dez pisos salariais. A nosso sentir a cobertura deste seguro se destina à acidente de tra- balho com resultado morte ou invalidez permanente.

As práticas que deveriam ser implantadas pelas transportadoras se baseando nas leis em vigor para a categoria e no QVT, temos como sugestão e apoio para novos programas de qualidade de vida para os trabalhadores, trazendo novas ideias de programas que podem ser implantados sem interferir em custo alto, podendo trazer incentivo e satisfação para seus colaboradores como:

\subsection{CRIAÇÃO DE PROGRAMAS DE QUALIDADE DE VIDA AO TRABALHADOR.}

A criação dos Programas de Qualidade de Vida do Trabalhador, tem como foco respaldar as necessidades do trabalhador, criando o bem-estar e a satisfação no ambiente de trabalho.

Segundo Chiavenato, (2010) a QVT elevada conduz a um clima de confiança e respeito mútuo, no qual as pessoas tendem a aumentar as suas contribuições, elevando suas oportunidades de êxito psicológico, enquanto a administração rígida tende a reduzir mecanismos rígidos de controle social.

Esses programas de qualidade de vida organizacional, incentiva a produção e a autorrealização de seus funcionários, ocorrendo assim a lucratividade de serviços, ou seja, se uma empresa investe em seus funcionários, os mesmos se sentirão motivados a tal ponto de desenvolver seu trabalho com autonomia e vontade.

Se há funcionários motivados a produção tende a ter uma qualidade superior, pois as chances de erros diminuem significativamente.

Por isso, através de poucas ações as empresas buscam a QVT de forma até de concorrerem a competitividades no mercado.

A seguir observamos algumas sugestões para o começo da implantação do programa. 
Quadro 4 - Sugestões para a QVT da categoria.

\begin{tabular}{|c|c|}
\hline Nas férias & $\begin{array}{l}\text { Premiações em dinheiro; } \\
\text { Vale desconto para clubes e viagens. }\end{array}$ \\
\hline Premiações & Ingressos para Programas Culturais. \\
\hline Saúde & $\begin{array}{l}\text { Psicólogo; } \\
\text { Ginástica Laboral; } \\
\text { Nutricionista local quinzenal. }\end{array}$ \\
\hline Programas & Dicas de alimentação via mensagem. \\
\hline Vale desconto & $\begin{array}{l}\text { Lojas de vestuários diversos; } \\
\text { Restaurantes; } \\
\text { Parques. }\end{array}$ \\
\hline Folgas extras & $\begin{array}{l}\text { Por desempenho de serviço; } \\
\text { Por datas comemorativas, como por exemplo: aniversários }\end{array}$ \\
\hline Hospedagens & Parceria com pensão no trajeto para melhor a comodidade para descanso \\
\hline Local para descanso confortável & Locais para descanso enquanto os motoristas aguardam a reposição de cargas. \\
\hline Atividade familiar na baixa safra & Atividades de recreação e lazer propostas pela empresa. \\
\hline $\begin{array}{l}\text { Formas de Remuneração e } \\
\text { Auxílios: }\end{array}$ & $\begin{array}{l}\text { Remuneração por competências e habilidades; } \\
\text { Remuneração variável; } \\
\text { Participação nos lucros e resultados (PLR). }\end{array}$ \\
\hline Oportunidades & $\begin{array}{l}\text { Plano de Carreira } \\
\text { Bolsas de Estudo, conforme rendimento; } \\
\text { Assembleias }\end{array}$ \\
\hline Serviço de lavanderia & Serviços de lavanderia em viagens longas. \\
\hline Kit de primeiros socorros & Para situações de emergência. \\
\hline
\end{tabular}

\section{CONCLUSÃO}

O trabalho de conclusão de curso TCC faz um analise reflexiva da qualidade de vida no trabalho. Considerando os níveis de abordagem como QVT, higiene, estresse, motivação, legislação.

Atualmente com a chegada de modernidades os avanços tecnológicos as empresas vêm cada vez mais investindo na produtividade e competitividade. Diante desse processo de globalização e do capital econômico tem-se investido bem, porém, o que faz com que os colaboradores de uma empresa tenham melhor desem- penho, demostrando melhor produtividade organizacional, para tanto o termo qualidade de vida no trabalho vem se disseminando trazendo um discurso relevante para esses colaboradores, e esse espaço de discussão e o que faz com que as melhorias aconteçam dentro desse processo de produtividade.

Assim fica claro que a qualidade de vida do indivíduo também depende da qualidade de vida no trabalho, pois o trabalho assume papel central na vida das pessoas. Qualidade de vida é trabalhar onde se sente bem com transparência nas relações internas, equilíbrio econômico e criatividade. 


\section{REVISTA}

Terceiro Setor \& Gestão

\section{REFERÊNCIAS}

ANTT. Disponível em: <http://www.antt.gov.br/index. php/content/view/4961.html>. Acesso em: 10 maio 2016.

ASCOM. Disponível em: <file:///C:/Users/280106527/ Downloads/arquivo_ascom_impresso.pdf>. Acesso em: 13 maio 2016.

BRASIL ESCOLA. Disponível em: <http://meuartigo. brasilescola.uol.com.br/administracao/influencia-qualidade-vida-no-trabalho-sobre-produtividade. htm>. Acesso em: 13 maio 2016.

CHIAVENATO, Idalberto. Remuneração, Benefícios e Relações de Trabalho. 6.ed. São Paulo: Manole, 2009. 246 p.

FERREIRA, Patrícia Itala. Clima organizacional e Qualidade de Vida no Trabalho. Série MBA Gestão de Pessoas. 1.ed. 2013.

PEREIRA, Ana Maria T. Benevides. Burnout: Quando o trabalho ameaça o bem-estar do trabalhador. 4.ed. São Paulo: Casapsi, 2010. 282 p.
NESDA. Disponível em: <http://gc.nesda.com. br/Conteudo/Arquivos/Biblioteca/Artigos $\% 20$ T\%C3\%A9cnicos/Artigos $\% 20 B \% C 3 \% A 1$ sicos $\% 20$ de $\% 20$ Neuroimunomodula $\%$ C 3 \% A7\% C3\%A3o/ estress_e_trabalho.pdf>. Acesso em: 13 maio 2016.

TRACKINGSYSTEM. Disponível em: <http://www. trackingsystem.com.br/solucoes.aspx. Acesso em: 13 maio 2016.

UOL. Disponível em: <http://jcrs.uol.com.br/site/noticia.php?codn=46723. Acesso em: 13 maio 2016.

SCIELO. Disponível em: <http://www.scielo.br/scielo.php? script=sci_arttext\&pid =S0102-88392003000200008. Acesso em: 12 maio 2016.

SETCESP. Disponível em: <http://www.setcesp.org. $\mathrm{br} /$ noticias-visualizar/ver/17633>. Acesso em: 08 maio 2016.

WALGER, C. et al. Motivação e satisfação no trabalho: Em busca do bem-estar de indivíduos e organizações. 1.ed. São Paulo: Intersaberes, 2014. 244p. 